\title{
Hopelessness and the Attitude Towards Cardiovascular Diseases
}

\author{
Mihai Marian \\ University of Oradea, Department of Psychology
}

Received 20 March 2018 • Revised 30 May 2018 • Accepted 12 June 2018

\begin{abstract}
This study focuses on the extent to which hopelessness depression theory is applicable in the field of psycho-cardiology. The study assesses the relation between hopelessness depression symptoms in patients having cardiovascular problems and the adherence to treatment or life quality. The participants to this research were interviews and assessed with a set of scales meant to identify the objectives of the study. The results indicate an adequate internal consistency for the scales used in the study. The identified predictors are $34.4 \%$ relevant in the case of hopelessness depression symptoms and $17.6 \%$ relevant in the case of the attitude towards cardiovascular diseases. The implications of the predictors are discussed and correlated with some suggestions regarding the need for counselling or the need for prevention programs.
\end{abstract}

Keywords: hopelessness, attitude, depression, cardiovascular diseases.

\section{Introduction}

The quality of life represents a multidimensional concept aiming the well-being including the emotional status, physical functioning and well-being (Abeles et al., 1994; Thommasen \& Zhang, 2006). At the opposite, the chronical diseases imply some adaptation processes which depend on factors such as: functional constraint, the significance given to the modifications, the period in which there appear modifications, losses, social influence and the culture (Marian, 2013).

Hart failure is a frequent diagnosis in the hospitalised patients from industrialised countries and the mortality rate caused by acute heart failure is roughly 30\%. More than half of the deaths occur before the individual reaches the hospital (Fauci et al., 2003). The pain occurs in the central region of the thorax and/or epigastrium, sometimes at the level of the arms, abdomen, back, mandible and neck. Frequently the pain comes with weakness, sweat, nausea, anxiety and the sensation of imminent death (Fauci et al., 2003; Marian, Drugaș \& Roșeanu, 2005).

In 1979 Schoolmeister indicated that the evolution of heart failure implies: the stress phase, the disorganization phase and the reconstruction one. The reactions of the patient in terms of duration and intensity during these phases depend on a series of personality traits (type A behaviour) and on a set of patients' circumstantial aspects (Marian, 2004).

Being labelled as "cardiacs", the patients with chronical cardiovascular diseases gain a special social status, related to the need for being protected against a series of stress factors.

(C) Authors. Terms and conditions of Creative Commons Attribution 4.0 International (CC BY 4.0) apply. Correspondence: Mihai Marian, University street 5, 410087 Oradea, ROMANIA. E-mail: mmarian@uoradea.ro. 
To the sources of psychical stress there are added, usually unconfessed, the perspectives of sudden death (mainly in the patients who have previous history of heart failure) or some redoubtable complications (strokes which can cause paresis and paralysis, pulmonary oedema in hipertension or valvulars, etc.). The perspective of stroke relapse or its complications creates a condition of permanent fear; this is the expression of psychical stress on different intensity degrees which will have a negative impact on the evolution of the main heart disease.

\section{Chronical disease and hopelessness}

Disabling diseases can determine a helplessness conditions, hopelessness and disutility feelings, lack of will and interest; all these feelings cause the decrease of treatment adherence, the inobservance of therapeutic prescriptions which may lead to complications and to worse evolution of the patient (Marian, 2006; 2013).

The association of depression with chronical diseases is frequently estimated in a third of the subjects diagnosed with these diseases. The researches previously conducted (Barefoot et al., 2000) indicated that around 50\% of the patients with heart attack were diagnosed with depression. Symptoms such as pain and asthenia are amplified by depression and may cause difficulties in therapeutic intervention. Depression may also determine people to withdraw from usual activities and to cause social isolation (Chung et al., 2008).

Abramson, Metalsky and Alloy (1989) and Metalsky and Joiner (1997) claimed that hopelessness depression symptoms include: delay of voluntary answer, sadness, suicidal ideation, lack of energy, apathy, psycho-motorial retard, sleep disorders, lack of attention and negative cognitions. The testing of hopelessness depression symptoms represents an approach for the assessment of depressive symptoms in an individualised manner (Marian, 2012a-b; Marian, 2013).

Barefoot et al. (2000) indicated that the presence of depressive symptoms influences in a negative manner the prognosis in cardiovascular diseases. Depression is manifested by a series of symptoms which not necessarily appear together. Fatigue and demoralizations feelings are indicators of vital exhaustion and they are seen as potential predecessors of heart attack. This information has important inferences for identifying the classes of symptoms which need improvement and for identifying the patients who could use therapeutic interventions.

Carney et al. (1995) investigated the impact of depression on health and concluded that depression and the uselessness feeling represent a risk for the incidence of cardiovascular diseases. The risk for cardiovascular diseases was even more pronounced in the case of depressive participants who presented uselessness feelings and were smokers.

The impact of disease related believes on depressive symptoms for the patients with cardiovascular diseases was examined by Stafford, Berk and Jackson (2009). Researchers examined the relations between the disease related believes and life quality. Negative believes related to negative consequences of the disease were associated with the enhancement of depressive symptoms three and nine months after the diagnosis was set. A positive attitude towards diseases was significantly associated with an increase of life quality. Older participants presented more negative attitudes towards diseases. These attitudes can be identified and modified by psycho-therapeutic cognitive-behavioural means which aim at decreasing psychological morbidity and at increasing patients `life quality after heart attack.

Chung et al. (2008) indicated that emotional distress in close persons is associated with the decrease of life quality for the cardiovascular disease patient. Consequently, the partner `s emotional distress has a negative impact on the cardiac patient's life quality, because he is vulnerable to the emotional distress of his close person. From theoretical point of view, the 
emotions are transferred to another person when two individuals have a close emotional relationship. In order to improve life quality for the patients with cardiovascular diseases, depressive symptoms and anxiety should be assessed for both life partners.

The way in which the patient with heart attack perceives the disease represents a key factor in the recovery process. Petrie, Cameron, Ellis, Buick and Weinman (2002) investigated through short term psycho-therapeutic interventions the consequences of changing the negative attitude towards diseases; the proved that when discharged, the patients had a high degree of optimism, strong believes regarding the management of the disease and the recovery and the anxious symptoms were diminished. The intervention proposed by them differs from regular recovery programs for the patients with cardiovascular diseases because it was deployed during hospitalization.

The intervention in the hospital frequently allows the early modification of irrational convictions and of the attributional dis-adaptive style until recovery, the patients being more receptive to change.

Other relevant studies reported significant relations between depression and the way patients perceive social support (Marian, 2006; 2013), proving that the relation between depression and death caused by cardiac diseases decreases when social support is higher (Marian, Drugaș \& Roșeanu, 2005; Marian, 2013).

\section{Objectives}

We proposed to observe the extent to which hopelessness symptoms differ according to a set of social cognitive criteria. According to the participants' attitude towards disease, we observed weather the hopelessness symptoms are more accentuated in the patients with surgical interventions. We also observe the extent to which demographic variables could be relevant predictors for negative attitude towards disease.

\section{Method}

\subsection{Participants}

There were 143 participants included in this study. There were 74 women (51.7\%) and 69 men (48.3\%); the marital status indicates that 92 (64.3\%) are married and 51 (35.7\%) are not married. All the participants volunteered and the group was formed out of 68 non-clinical participants (healthy) and 75 participants diagnosed with heart attack. From the age point of view, 41 participants are 50 years old (28.7\%), 66 are aged between $51-70$ years old (46.2\%) and 36 were over 71 years old $(25.2 \%)$.

\subsection{The instruments used}

Hopelessness Depression Symptom Questionnaire (Metalsky \& Joiner, 1997) is designed in order to assess some uselessness symptoms in the case of depression. It is an instrument made of 32 items which include eight subscales. Alpha coefficients for each subscale were (see Marian, 2012b, 2013): (a) motivational deficit (retarded initiation of voluntary responses; .83); (b) interpersonal dependency (.77); (c) psychomotor retardation (.83); (d) lack of energy (.89); (e) apathy/anhedonia (.83); (f) insomnia (.90); (g) concentration difficulty (.73); and (h) suicidality (.75). The alpha coefficient for the full HDSQ was .95.

Illness Attitudes Scale (IAS) elaborated by Kellner, Slocumb, Wiggins, Abbott, Winslow and Pathak (1985) indicates the way in which the patient approaches the disease. The IAS comprises several subscales - worry about illness, concern about pain, health habits, 
hypochondriacal beliefs, thanatophobia, disease phobia, bodily preoccupation, treatment experiences, and effects of symptoms. Kellner et al. (1985) reported a good internal consistency ( $\alpha$ between .62 and .92). A high score indicates a negative attitude towards the disease.

Quality of Life Scale (QLS) was elaborated by Cowan and Kelly in The American Chronic Pain Association, in 2003 (www.theacpa.org). This scale performs an assessment for the functioning ability rather than for the pain itself; the scale is meant to help the patient and the healthcare team to assess and to communicate the impact of pain on everyday activities. The scale included 11 items, counted from o to 10, where o stands for no functioning and 10 stands for normal functionality. The items include descriptions of the patient's daily activities and he should chose only one item which best describes his situation at the moment of the assessment.

\section{Work procedure}

The instruments used were applied without a dead line from the examiner. In the design of the research there were included: demographical and clinical information, the number of hospitalizations, surgical interventions, the diseases associated with the main diagnosis.

Design. The objectives target a multifactorial experimental design. Considering that the predictors are number and continuous variables we use regression in predictive purpose.

\section{The interpretation of the results}

According to the previously presented objectives, we discovered the differences in the case of hopelessness depression symptoms according to the type of participants.

The statistical analyses reveals the existence of some differences between the averages for hopelessness depression symptoms according to gender $(t=2.55(141) ; p<.01 ; d=0.42)$ and this confirms the significant differences between the two groups. The women present more accentuated symptoms representative for hopelessness depression as compared to men.

In the case of the attitude towards the disease, the married participants manifest a higher negative attitude towards the disease as compared to the participants who are not married $(\mathrm{t}=1.87(141) ; \mathrm{p}<.05 ; \mathrm{d}=0.21)$ without measuring a significant difference between genders.

The registered results support the initial predictions about the differences between the participants reported to the frequency of hopelessness depression symptoms according to the number of hospitalizations $[\mathrm{F}=2.481(61 ; 142) ; \mathrm{p}<.001]$. Consequently, an increased number of hospitalizations significantly influences hopelessness depression symptoms in the way that they are more frequent.

\subsection{Predictions about the prevalence according to age, gender and the quality of life}

We postulate that age, gender and the quality of life are relevant predictors in estimating hopelessness depression symptoms for the heart attack hospitalised patients.

The data presented in Table 1 explain in adjusted form a proportion of 50.3\% $(\mathrm{R} 2=.503)$ the dispersion of the evolution for hopelessness depression symptoms in the case of heart attack participants. 
Table 1. Simple linear regressions predicting hopelessness depression symptoms

\begin{tabular}{llllllllll}
\hline \multicolumn{1}{c}{ Prediction } & $F_{(3,142)}$ & $R$ & $R^{2}$ & $B$ & $S E B$ & $\beta$ & $t$ & $p$ & $p r$ \\
& 46.959 & .709 & .503 & & & & & & \\
Age & $\mathrm{p}<.001$ & & & & & & & & \\
Gender & & & & 11.33 & 1.92 & .41 & 5.88 & .001 & .352 \\
Quality of life & & & & -5.67 & 2.42 & -.14 & -2.33 & .02 & -.140 \\
\hline
\end{tabular}

Note 1: Predictors: age; gender; quality of life; Dependent Variable: hopelessness depression symptoms.

Note $2:{ }^{*} p<.05 ;{ }^{* *} p<.01 ; S E=$ standard error; $\mathrm{B}=$ unstandardized coefficients;

$\beta=$ standardized coefficients; $\mathrm{pr}=$ semipartial correlation.

The regression equation indicates that women who suffered from heart attack tend to be more sensitive in developing specific rather than men $(B=-5.671 ; t=-2.33, p<.02 ; p r=.14)$; a decrease for the quality of life with 12,609\% shall come along with the enhancement of hopelessness depression symptoms for the participants with heart attack $(B=-12.609 ; t=-5.32$, $\mathrm{p}<.001, \mathrm{pr}=.31)$. In this context the age is a major predictor for the heart attack participants $(\mathrm{B}=11.332 ; \mathrm{t}=5.88, \mathrm{p}<.001, \mathrm{pr}=.35)$.

\subsection{Predictions about the prevalence according to age, hopelessness depression and the quality of life}

The regression was additionally applied in order to establish whether hopelessness depression symptoms, the quality of life and the age of the participants could be predictors for the negative attitude towards disease. The statistical data obtained explain a proportion of $27.1 \%$ $(\mathrm{R} 2=.271)$ from the evolution of negative attitude dispersion towards disease (see Table 2).

Table 2. Simple linear regressions predicting attitude towards disease

\begin{tabular}{llllllllll}
\hline \multicolumn{1}{c}{ Prediction } & $F_{(3,142)}$ & $R$ & $R^{2}$ & $B$ & $S E B$ & $\beta$ & $t$ & $p$ & $p r$ \\
& 17.182 & .520 & .271 & & & & & & \\
Age & $\mathrm{p}<.001$ & & & & & & & & \\
Quality of life & & & & -.57 & 1.76 & -.03 & -.32 & .74 & -.023 \\
HDS & & & & -3.92 & 2.12 & -.17 & -1.84 & .05 & -.134 \\
\hline
\end{tabular}

Note 1: Predictors: age; quality of life; hopelessness depression symptoms; Dependent Variable: attitude towards disease.

Note $2:{ }^{*} p<.05 ;{ }^{* *} p<.01$; HDS $=$ hopelessness depression symptoms; $S E=$ standard error; $\mathrm{B}=$ unstandardized coefficients; $\beta=$ standardized coefficients; $\mathrm{pr}$ = semipartial correlation.

In this context a decrease for the quality of life with $3.9 \%$ shall lead to the increase of negative attitude towards disease $(\mathrm{B}=-3.925 ; \mathrm{t}=-1.84, \mathrm{p}<.05, \mathrm{pr}=.134)$; besides that, the results suggest that young people with heart attack and hopelessness depression symptoms are more vulnerable to develop a difficult adaptive attitude $(\mathrm{B}=.284 ; \mathrm{t}=4.16, \mathrm{p}<.001, \mathrm{pr}=.302)$.

\section{Conclusions}

The impact of chronical disease on physical and psychical functioning shall determine the way in which the patient perceives the symptoms, the severity, the evolution and the treatment of the disease. The attitude towards disease and the perception of social support represent important factors both in maintaining the health and in the process of recovery from the disease. 
The attitude towards disease differs according to the marital status of the patients with heart attack, in the way that a higher emotional contagion is possible for married persons and implicitly negative reactions, as Chung et al. (2008) claimed in a different context. Our data suggest that the patient's negative attitude towards disease is more intense if the life partner adopts the same attitude.

In consonance with the results of Carney et al. (1995), we confirm that hopelessness depression symptoms are relevant predictors for the development of cardiovascular diseases.

Hopelessness depression symptoms were analysed even according to the number of hospitalizations for the participants who had no surgical interventions. The results confirmed that the number of hospitalizations significantly influences the symptoms, so the participants with more than three hospitalizations present the most accentuated hopelessness depression symptoms. Hospitalization itself makes the patient believe he is in the helplessness condition maybe even because of the fact that many times the patient is hospitalised during an emergency case when he cannot control the somatic symptoms he manifests. The increase of hospitalization incidence may aggravate the psychological equilibrium of the individual.

On the other hand, the decrease of life quality for the patients with heart attack may generate the intensification of hopelessness depression symptoms. The regression equation suggests that the decrease of life quality shall increase the negative attitude towards the disease, especially in young people.

Optimising the accommodation with the disease by early implementing psychological programs could have the purpose of improving the attitude towards the disease even during hospitalization. The hospitalised patients with cardiovascular diseases are more receptive to change. As Petrie et al. (2002) claimed, the patients who benefit from psychological interventions and counselling are more optimistic when released from hospital, they manifest believes regarding the disease management and they are confident about the ways of recovery. The perception of social support towards the dangers perceived as being imposed by cardiovascular diseases has a major role in respecting the treatment (Marian, 2004; 2006; Sayers et al., 2008) also being an essential factor for decreasing the mortality (Lam \& Lauder, 2000).

Finally we consider that the assessment of the patients should also measure even the extent to which the patients could make some major life changes imposed by the symptoms of their disease, and their ability to respect complex therapeutic indications. In this respect, the psychological assessment of the patient's close persons would be relevant. Chung et al. (2008) claimed that the emotional distress of a close person could be associated with the decrease of life quality for the patient with heart attack. We consider that the implementation of programs aiming both the patient and the person who gives him support and who looks after him, would be the most efficient.

\section{Acknowledgements}

This research did not receive any specific grant from funding agencies in the public commercial, or not-for-profit sectors.

The author declares no competing interests. 


\section{References}

Abeles, R. P., Gift, H. C., \& Ory, M. G. (1994). Aging and quality of life. New York: Springer Publishing.

Abramson, L. Y., Metalsky, G. I., \& Alloy, L. B. (1989). Hopelessness depression: A theory-based subtype of depression. Psychological Review, 96(2), 358-372.

Barefoot, J. C., Brummett, B. H., Helms, M. J., Mark, D. B., Siegler, I. C., \& Williams, R. B. (2000). Depressive symptoms and survival of patients with coronary artery disease. Psychosomatic Medicine, 62, 790-795.

Carney, R. M., Freedland, K. E., Rich, M. W., \& Jaffe, A. S. (1995). Depression as a risk factor for cardiac events in established coronary heart disease: A review of possible mechanisms. Annals of behavioral medicine, 17(2), 142-149.

Chung, M. L., Moser, D. K., Lennie, T. A., \& Rayens, M. K. (2008). The effects of depressive symptoms and anxiety on quality of life in patients with heart failure and their spouses: Testing dyadic dynamics using Actor-Partner Independence Model. Journal of Psychosomatic Research, 67, 29-35.

Fauci, A. S., Braunwald, E., Isselbacher, K. J., Wilson, J. D., Martin, J. B., Kasper, D. L., Hauser, S. L., \& Longo, D. L. (2002). Harrison - Principiile medicinei interne [Principle of internal medicine], Vol. I-II, Bucureşti: Teora.

Kellner, R., Slocumb, J., Wiggins, R. N., Abbott, P. J., Winslow, W. W., \& Pathak, D. (1985). Hostility, somatic symptoms and hypochondriacal fears and beliefs. Journal of Nervous and Mental Disease, 173, 554-560.

Lam, C. L. K., \& Lauder, I. J. (2000). The impact of chronic disease on the health-related quality of life (HRQOL) of Chinese patients in primary care. Family Practice, 17, 159-166.

Marian, M. (2004). Introduction to clinical psychology. Oradea: Editura Universitatii din Oradea.

Marian, M. (2006). Validation of the multidimensional scale of perceived social support. Psychometric characteristics. Analele Universităţii din Oradea, Fascicula Psihologie, 10, 21-35.

Marian, M. (2012a). Hypothetical causal model of learned helplessness through structural modelling: experimental data. In: K. N. Fountoulakis (Ed.), 2nd International Congress on Neurobiology, Psychopharmacology \& Treatment Guidance, Thessaloniki, Greece, November 24-27, 2011 (pp. 93-98). Pianoro (Bologna) Italy: Medimond International Proceedings.

Marian, M. (2012b). Trial of hopelessness theory by the use of modelling. New psychometric data on the Hopelessness Depression Symptom Questionnaire. Journal of Psychological and Educational Research, 2O(1), 45-58.

Marian, M. (2013). Implications of learned helplessness in social problems and physical health. International Journal of Education and Psychology in the Community, 3(2), 7-10.

Marian, M., Drugaș, M., \& Roșeanu, G. (2005). Psychological perspective of health and disease. Oradea: Editura Universitatii din Oradea.

Metalsky, G. I., \& Joiner, T. E. (1997). The Hopelessness Depression Symptom Questionnaire. Cognitive Therapy and Research, 21(3), 359-384.

Petrie, K. J., Cameron, L. D., Ellis, C. J., Buick, D., \& Weinman, J. (2002). Changing illness perceptions after myocardial infarction: An early intervention randomized controlled trial. Psychosomatic medicine, 64, 580-586. 
Sayers, S. L., Riegel, B., Pawlowski, S., Coyne, J. C., \& Samaha, F. F. (2008). Social support and self-care of patients with heart failure. Annals of Behavioral Medicine, 35, 70-79.

Stafford, L., Berk, M., \& Jackson, H. J. (2009). Are illness perceptions about coronary artery disease predictive of depression and quality of life outcomes? Journal of Psychosomatic Research, 66, 211-220.

Thommasen, H. V., \& Zhang, W. (2006). Impact of chronic disease on quality of life in the Bella Coola Valley. Rural and Remote Health, 6, 1-18.

http://www.theacpa.org/documents/Quality of Life Scale.pdf 